\title{
An innovative nipple reconstruction technique for minimizing postoperative scars: The teardrop flap
}

\author{
Bong Gyu Choi, Il-Kug Kim \\ Department of Plastic and Reconstructive \\ Surgery, Yeungnam University College of \\ Medicine, Daegu, Korea
}

Keywords Mammaplasty / Nipples / Surgical flaps

\begin{abstract}
Nipple reconstruction methods include various techniques, such as the local flap technique, free nipple grafting, and filler injection. The local flap technique can provide less donor site morbidity than a free nipple graft, but leaves an additional scar near the nipple. We present a novel method for reconstruction of the nipple using a flap located on one side of the nipple. The flap has a teardrop shape consisting of a circle and two wings folded to one side. The two wings form a pillar and cap, and the de-epithelialized tip of one wing fills the internal dead space of the new nipple. We applied this nipple reconstruction technique in the case of a 61-year-old patient who had a vertical scar due to inverted-T reduction mammoplasty. The patient had lost her nipple in previous breastconserving surgery. The immediate postoperative nipple projection was $10 \mathrm{~mm}$. At the 7-month follow-up visit, the nipple projection was $7.5 \mathrm{~mm}$. The teardrop flap is an innovative technique that leaves no additional scar by using the scar already present on one side of the nipple.
\end{abstract}

This article was presented at the PRS Korea 2019 conference on November 8-10, 2019, in Seoul, Korea.
This study was supported by the National Research Foundation of Korea (NRF2018R1C1B6004618 to Il-Kug Kim).

\section{INTRODUCTION}

Nipple-areolar complex (NAC) reconstruction greatly improves satisfaction with overall breast reconstruction in patients with NAC loss due to breast cancer excision [1]. Recreating the NAC is generally the last step of breast reconstruction because it cannot be performed until the breast configuration is stabilized after breast mound reconstruction. NAC reconstruction methods include one or more of the following techniques: the local flap technique, free nipple grafting, the use of autogenous implants, and filler injection [1-3].

In the local flap technique, the epidermis, dermis, and subcutaneous tissue are used in a variety of patterns, such as the $\mathrm{C}-\mathrm{V}$ flap, arrow flap, and boomerang flap [4-6]. Although local flaps provide

Received: Nov 30, 2019 Revised: Jan 6, 2020 Accepted: Jan 7, 2020 Correspondence: Il-Kug Kim Department of Plastic and Reconstructive Surgery, Yeungnam University College of Medicine, 170 Hyeonchung-ro, Nam-gu, Daegu 42415, Korea

Tel: +82-53-620-3481, Fax: +82-53-626-0705, E-mail: curingyou@gmail.com

Copyright $\odot 2020$ The Korean Society for Aesthetic Plastic Surgery.

This is an Open Access article distributed under the terms of the Creative Commons Attribution Non-Commercial License (https://creativecommons.org/licenses/by-nc/4.0/) which permits unrestricted non-commercial use, distribution, and reproduction in any medium, provided the original work is properly cited. $\quad w w w . e-a a p s . o r g$ less donor site morbidity than free nipple grafting, their use leaves an additional scar. Therefore, if a previous mastectomy scar is located near the nipple, a flap that includes the scar is elevated in order to minimize the scar. However, mastectomy scars are usually located on only one side of the nipple, so an additional scar on the opposite side is inevitable when utilizing current techniques that require flaps on both sides of the nipple. Herein, we present a novel method for nipple reconstruction without leaving an additional scar by using a teardrop-shaped flap located on only one side of the nipple.

\section{IDEA}

NAC reconstruction was performed using a vertical scar on a 61-yearold patient who had undergone an inverted-T reduction mammoplasty. The patient had lost her NAC prior to reduction mammoplasty in previous breast-conserving surgery (BCS) with nipple resection.

The new technique proposed in this paper utilizes a modified boomerang flap that has a reverse teardrop shape with two wings folded to one side (Fig. 1). First, the patient takes a sitting position, and a circle is drawn on the site where the new nipple is to be located. The radius of this circle will be the height of the new nipple, 
and taking into account the expected postoperative decrease in nipple size, the radius of the circle should be 1.5 times larger than the height of the opposite nipple. Then, the clinician marks the wing's tip, which is located at four times the radial distance from
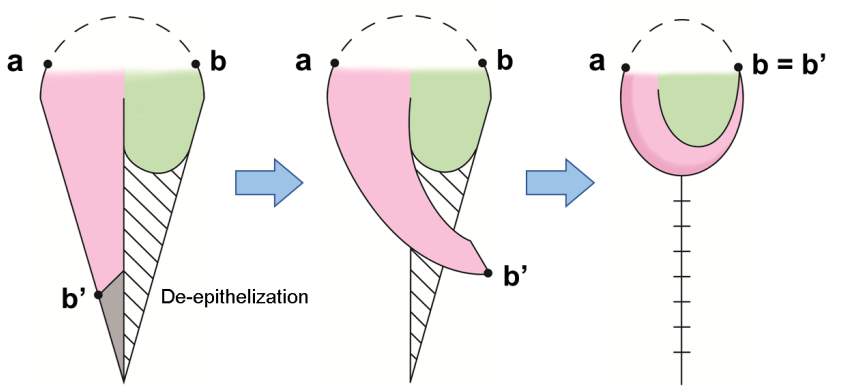

Fig. 1. The flap had a reverse teardrop shape with a circle and two wings folded to one side. In this case, the wing's tip was located at four times the radial distance from the center of the circle. The dotted line between the two points $(a, b)$ indicates the part that was preserved without an incision. The distal part of one wing was resected. The proximal part of the wing (b') was rolled to form a cylinder. The opposite wing formed a lid, and the distal part of wing was de-epithelialized to fill the dead space inside the nipple. the center of the circle along the direction of the scar, and two tangential lines are drawn from that point to the circle's border. The location of the tip can be determined based on the projection of the contralateral nipple.

An incision is made using a No. 15 blade, leaving out one-third of the circle opposite the wing, and the designed flap is elevated. Then, the wing is rolled cylindrically. The remaining distal part of the wing is excised or de-epithelialized for use in filling the dead space inside the nipple to provide greater volume. The opposite wing forms a lid, and the distal portion of the wing is also de-epithelialized and used similarly. Although it was not utilized in this case, acellular dermal matrix can be used for the maintenance of nipple projection if the subcutaneous tissue is thin. The nipple and donor sites are closed using a simple suture technique, and a silastic drain is placed inside the donor site and removed the next day (Fig. 2).

The immediate postoperative projection of the nipple was $10 \mathrm{~mm}$, whereas it was $9 \mathrm{~mm}$ and $7.5 \mathrm{~mm}$ at 1 and 7 months after surgery, respectively. In addition, the patient underwent a tattooing procedure for areolar reconstruction 4 months after nipple reconstruction (Fig. 3).
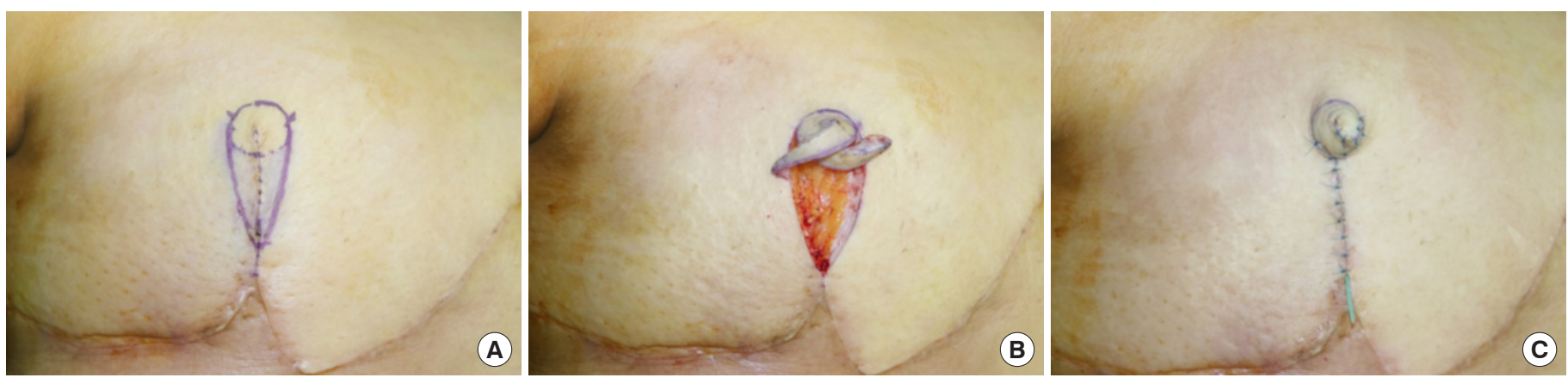

Fig. 2. (A) Preoperative design of the teardrop flap. (B) Dissection was performed, leaving out one-third of the circle on the opposite side of the wings. (C) The nipple and donor site was closed using a simple suture technique.
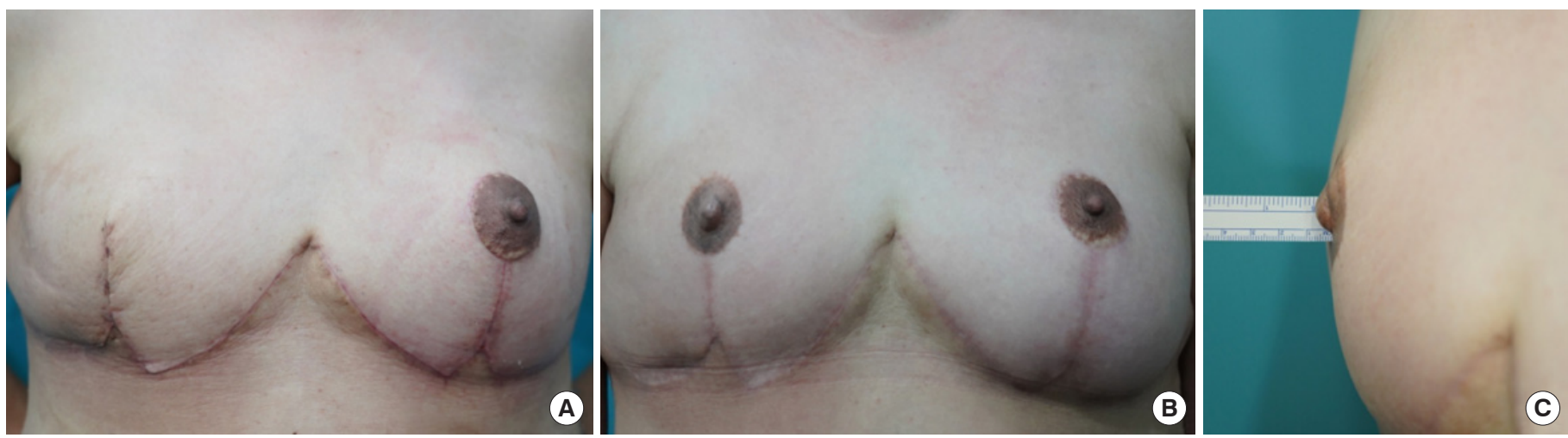

Fig. 3. (A) Preoperative image. (B) Seven months after surgery. (C) The nipple projection at 7 months after surgery was $7.5 \mathrm{~mm}$. 


\section{DISCUSSION}

Nipple reconstruction improves patients' satisfaction with the aesthetic results of reconstruction, and it can be easily performed under local anesthesia. Various methods have been developed for nipple reconstruction and are performed according to the patient's condition and the surgeon's preference. Nevertheless, there is no magic-bullet nipple reconstruction method that is ideal for all cases. Free nipple grafting has the advantage of providing a new nipple with a similar texture and pigmentation as the other nipple [1]. However, this technique may not be feasible, as it depends on the size of the opposite nipple and on the morbidity at the donor site [7]. Conversely, although it is possible to perform nipple reconstruction with a local flap regardless of the size of the contralateral nipple, an additional scar cannot be avoided when such a local flap technique is used. For patients who have previously undergone operations such as mastectomy or reduction mammoplasty, nipple reconstruction using a local flap designed along the previous scar can be a desirable method.

However, most mastectomy scars and reduction mammoplasty scars are located on one side of the nipple. Since existing methods such as the $\mathrm{C}-\mathrm{V}$ flap, arrow flap, and boomerang flap require flaps on both sides of the nipple, an additional scar is inevitable [4-6]. Our method involves the elevation of a flap from only one side of the nipple, so the formation of an additional scar can be avoided.

In the present case, the patient had previously undergone BCS with NAC excision, and nipple reconstruction could have been performed using the existing BCS scar. However, as nipple construction should be the last step of breast configuration, it was performed after the patient's reduction mammoplasty using the vertical scar. The method described herein is also applicable to patients who have undergone mastectomy with an existing linear incisional scar in any direction adjacent to the nipple position.

This technique has two main limitations. The first limitation is the decrease in the volume of the breast mound at the donor site. Therefore, this technique should be performed when the tissues around the donor site have sufficient redundancy. Another limitation is that the smaller third of the circle on the opposite side may bulge in some cases. This complication can be resolved with an intraoperative pinch suture, although that technique was not performed in this study.

According to the literature, the size of the nipple decreases over the first 6 postoperative months after nipple reconstruction due to retraction forces from the surrounding tissues and tissue contraction of the flap [2]. The average reduction in nipple size observed when using a skate flap or star flap is $43 \%$, while our patient showed a reduction of only $25 \%$ [8]. This is because teardrop flaps are subdermal pedicled flaps that have a lower retraction force than centrally based flaps. Their design is simple, which causes less scarring and contracture [2]. Further case studies are required to clarify the reduction of nipple size using our reconstruction method. However, the teardrop flap is an easy method of nipple reconstruction that achieves a proper degree of projection and width without additional scar formation.

\section{NOTES}

\section{Conflict of interest}

IKK, an associate editor of Archives of Aesthetic Plastic Surgery, is the corresponding author of this article. However, he played no role whatsoever in the editorial evaluation of this article or the decision to publish it. Except for that, no potential conflict of interest relevant to this article was reported.

\section{Ethical approval}

The study was approved performed in accordance with the principles of the Declaration of Helsinki.

\section{Patient consent}

The patient provided written informed consent for the publication and the use of her images.

\section{ORCID}

Bong Gyu Choi ～https://orcid.org/0000-0003-0136-196X

Il-Kug Kim https://orcid.org/0000-0002-2428-8403

\section{REFERENCES}

1. Sisti A, Pica Alfieri E, Brandi C, et al. Nipple-areola complex reconstruction. Plast Reconstr Surg 2018;142:793e.

2. Farhadi J, Maksvytyte GK, Schaefer DJ, et al. Reconstruction of the nipple-areola complex: an update. J Plast Reconstr Aesthet Surg 2006; 59:40-53.

3. Kim YC, Yun JY, Lee HC, et al. Nipple reconstruction with combination of modified CV flap and contralateral nipple composite graft. J Plast Reconstr Aesthet Surg 2017;70:243-7.

4. Witt P, Dujon DG. The V-V flap: a simple modification of the C-V flap for nipple reconstruction. J Plast Reconstr Aesthet Surg 2013;66: 1009-10.

5. Guerra AB, Khoobehi K, Metzinger SE, et al. New technique for nipple areola reconstruction: arrow flap and rib cartilage graft for long-lasting nipple projection. Ann Plast Surg 2003;50:31-7.

6. Kim YE, Hong KY, Minn KW, et al. A novel nipple reconstruction technique for maintaining nipple projection: the boomerang flap. Arch Plast Surg 2016;43:470-3.

7. Zenn MR, Garofalo JA. Unilateral nipple reconstruction with nipple sharing: time for a second look. Plast Reconstr Surg 2009;123:1648-53.

8. Nimboriboonporn A, Chuthapisith S. Nipple-areola complex reconstruction. Gland Surg 2014;3:35-42. 